\title{
Analysis of characteristics of the cities on the warehouse location: the case of Belo Horizonte metropolitan region
}

\author{
Análises das características das cidades que influenciam na localização de \\ armazéns: o caso da Região Metropolitana de Belo Horizonte
}

\author{
Isabela Kopperschmidt de Oliveira ${ }^{1}$, Gracielle Gonçalves Ferreira de Araújo², \\ Leise Kelli de Oliveira ${ }^{3}$ \\ ${ }^{1}$ Federal University of Pernambuco, Pernambuco - Brazil, isa.kopper@gmail.com \\ ${ }^{2}$ Federal University of Minas Gerais, Minas Gerais - Brazil, gracielle.gfa@gmail.com \\ ${ }^{3}$ Federal University of Minas Gerais, Minas Gerais - Brazil, leise@etg.ufmg.br
}

\section{Recebido: \\ 6 de junho de 2021 \\ Aceito para publicação: \\ 25 de outubro de 2021 \\ Publicado: \\ 31 de dezembro de 2021 \\ Editor de área: \\ Renato da Silva Lima}

\section{Keywords:}

Urban freight transport.

Warehouse.

Spatial analysis.

Palavras-chave:

Transporte urbano de carga.

Armazéns.

Análise espacial.

DOI:10.14295/transportes.v29i3.2639

\begin{abstract}
The warehouse location is a critical factor in the efficiency of urban freight transport. However, several factors influence this location. This paper analyses the spatial correlation of characteristics of cities in a metropolitan region and the location of the warehouses through a case study in the Belo Horizonte metropolitan region. The municipalities' socioeconomic and fleet data were analysed using the Local Moran Index and Bivariate Moran Index statistics. The results were presented by clusters using the Local Indicator of Spatial Association. Populational density, land cost, and truck fleet are spatially correlated with the warehouses' location. Furthermore, the characteristics of some municipalities, as Contagem, Ribeirão das Neves, and Ibirité, create high-high clusters, with high spatial correlation in the municipalities of cluster and, also, in the surroundings. Findings suggest the importance of land use, logistics, and real estate sector public policies minimise warehouses' externalities and contribute to economic development.
\end{abstract}

\section{RESUMO}

A localização de armazéns logístico é um fator crítico na eficiência do transporte urbano de carga. No entanto, vários fatores influenciam esta localização. Este artigo analisa a correlação espacial das características dos municípios de uma região metropolitana e a localização dos armazéns por meio de um estudo de caso na região metropolitana de Belo Horizonte. Os dados socioeconômicos e da frota dos municípios foram analisados por meio do Índice de Moran Local e do Índice de Moran Bivariada. Os resultados foram apresentados por conglomerados por meio do Indicador Local de Associação Espacial. A densidade populacional, o custo da terra e a frota de caminhões estão espacialmente correlacionados com a localização dos armazéns. Além disso, as características de alguns municípios, como Contagem, Ribeirão das Neves e Ibirité, criam aglomerados alto-alto, com alta correlação espacial nos municípios do cluster e, também, no entorno. Os resultados sugerem a importância do uso do solo, da logística e das políticas públicas do setor imobiliário que minimizam as externalidades dos armazéns e contribuem para o desenvolvimento econômico.

\section{INTRODUCTION}

Activities related to urban freight transportation (UFT) have significant impacts on the urban landscape due to trade and the storage infrastructure (Giuliano et al., 2018). Therefore, UFT 
is essential for supplying cities in metropolitan regions (RMs) (Dablanc et al., 2013), and the warehouse is an essential infrastructure for this system (Giuliano and Kang, 2018; Kang, 2018). Several factors are cited in the literature as fundamental in the warehouse location, as:

- availability of areas for new warehouses (Jaller et al., 2017; Heitz et al., 2019; Heitz et al., 2020),

- cost of rental or acquisition (Verhetsel et al., 2015; Heitz et al., 2019; Heitz et al., 2020; Guerin et al., 2021),

- tax-free (Demirel et al., 2010),

- availability of labour (Demirel et al., 2010; Heitz et al., 2020),

- skilled labor (Demirel et al., 2010),

- employee accessibility (Heitz et al., 2019; Heitz et al., 2020),

- quality, availability, and reliability of transportation modes (Demirel et al., 2010),

- proximity to the final consumer (Demirel et al., 2010; Jaller et al., 2017; Heitz et al., 2018),

- proximity and accessibility to transport infrastructure (Jaller et al., 2017; Heitz et al., 2019; Heitz et al., 2020),

- land use and zoning (Demirel et al., 2010; Jaller et al., 2017; Guerin et al., 2021), and

- freight policies (Demirel et al., 2010; Jaller et al., 2017; Heitz et al., 2020).

The location of the warehouses impacts the public and private stakeholders (Aljohani and Thompson, 2016). From the public point of view, the location of the warehouses influences the transport flows and the quality of life of the residents, mainly due to the increase in noise and pollution levels, accidents, and congestion (Lindsey et al., 2014; Aljohani and Thompson, 2016). For the private sector, the location of warehouses influences the transportation costs and the efficiency of operations (Dablanc et al., 2014; Lindsey et al., 2014; Aljohani and Thompson, 2016). However, the freight policies related to warehouses are limited to land use (Aljohani and Thompson, 2016).

The location of warehouses in a metropolitan region is a research agenda explored by several researchers, mainly related to the logistics sprawl phenomenon (Heitz et al., 2019), defined as the decentralisation of warehouses in a metropolitan region (Dablanc and Rakotonarivo, 2010; Aljohani and Thompson, 2016). Several authors analysed the logistics sprawl in numerous metropolitan regions (Dablanc and Rakotonarivo, 2010; Sakai et al., 2016; Woudsma et al., 2016; Heitz et al., 2017; Jaller et al., 2017; Dubie et al., 2020; Heitz et al., 2020; Klauenberg et al., 2020; Woudsma and Jakubicek, 2020; Yuan and Zhu, 2019), including Brazilian metropolitan regions, as São Paulo (Guerin et al., 2021), Belo Horizonte (Oliveira et al., 2017; 2018), Palmas (Bracarense et al., 2018), and Curitiba (Sousa and Oliveira, 2021).

Among the factors that contribute to the logistics sprawl, we highlight the inadequate urban planning (Leigh and Hoelzel, 2012), land use (Dablanc and Rakotonarivo, 2010), land cost (Jakubicek and Woudsma, 2011; Allen et al., 2012; Verhetsel et al., 2015; Heitz et al., 2020), availability of land for expansion (Aljohani and Thompson, 2016), and transportation infrastructure (Aljohani and Thompson, 2016; Heitz et al., 2018; Oliveira et al., 2019). The taxonomy of logistics sprawl impacts was detailed by Aljohani and Thompson (2016).

However, few studies have analysed the influence of these factors on the spatial distribution of warehouses in a metropolitan region. For example, estimating a used zero-inflated logit 
model, Jaller et al. (2017) found that home value, the establishments from manufacturing and transportation sector, distance to the highway contribution to the location of the warehouse in South California. Also, the per capita income, population, adults using public transit mode, establishments from the manufacturing and transportation sector, neighbouring warehouse establishments, neighbouring accommodation and food services, and the distance to intermodal facilities contribute to the warehouse location (Jaller et al., 2017). Jaller et al. (2017) identified these factors by estimating a negative binomial model. The results of Jaller's study show that different techniques can include/remove the contributing factors to the location of warehouses.

Analysing Belo Horizonte, Oliveira et al. (2019) found the zoning, land cost, proximity of regional highways and main streets, population and retailer density are the factors with influence on warehouse location. In an empirical analysis, Heitz et al. (2020) revealed that the accessibility and availability of transport infrastructure attract warehouses in Gothenburg metropolitan area. Sousa and Oliveira (2020) showed the size of the metropolitan area in square meters, the number of cities and the retail business influences the concentration of warehouses in metropolitan areas of Paraná State, in Brazil. More recently, and using spatial analysis, Guerin et al. (2021) identified the municipalities with the concentration of warehouse per capita are surrounded by the high occurrence of cargo theft, high road extension, high land cost, and fleet in the Metropolitan Area of São Paulo.

Given the undeniable importance of warehouses for the UFT system, it is essential to understand the UFT phenomenon for effective freight policies for the economic development of a metropolitan region. González-Feliu (2018) reported that Latin American cities have difficulties in including fright mobility in urban planning. His inclusion is not mandatory while imperative or recommended in Europe and the United States. Dias et al. (2018) related the lack of knowledge about issues related to UFT for inclusion in transport policies in Brazilian cities. Due to the lack of importance of UFT in metropolitan planning, warehouses are located in lowcost areas as a cost reduction strategy, generally in peripheral regions and far away from the consumer market due to the transport operator's decision. Very rarely, the government has an influence on the location of warehouses in an RM.

Based on the identified issues, we proposed the following research question: Is there a spatial correlation between the warehouse's location and the city's characteristics in a metropolitan region? Therefore, this paper aims to analyse the spatial correlation of the warehouse's location in a metropolitan region, using public data from Belo Horizonte Metropolitan Region (BHMR). Furthermore, identifying factors that influence the warehouses' location can improve the understanding of the phenomenon, showing the importance of including freight in urban and metropolitan planning, in land-use policies, contributing to the well-being of the areas urban areas and the economic development of the metropolitan region.

Our proposal has similarity to those proposed by Guerin et al. (2021) for São Paulo Metropolitan Area, analysing other characteristics of the cities not included by Guerin et al. (2021), as consumer market represented by the shops, the employee rate, and the stratified categories of the fleet. We compared the results with Guerin et al. (2021). Also, we highlighted the importance of not generalising them due to the influence of the local characteristics on warehouse location. This paper's contribution is related to how the characteristics of the cities are contributing factors for the warehouse location. Furthermore, we demonstrated that 
each metropolitan context is unique, and the heterogeneous characteristics do not provide a spatial pattern.

This paper is structured in 5 sections. After this introductory section, the research method is explained in section 2; the study area is described in section 3; the results are detailed in section 4 . Finally, the conclusions are presented in section 5.

\section{RESEARCH METHOD}

The increase and availability of spatial data brought new issues concerning urban phenomena analysis. Geographically data sets are not independent due to spatial autocorrelation and spatial heterogeneity (Anselin, 1988). Since the urban phenomena are represented by data highly spatial correlation, it is essential to understand their correlation better.

Considering warehouse location as an urban phenomenon, we analysed the spatial autocorrelation among the warehouse location and characteristics of the cities that could influence the UFT, taking the municipality as the geographical unit. The variables considered in the analysis are presented in Table 1 . We used the employment rate, GDP per capita and service fee percentage (ISSQN) as variables related to economic development. Also, we consider some correlated fleet data: total fleet, motorcycle fleet and truck fleet. Motorcycles were included since more and more these vehicles are being used for freight deliveries, mainly fast deliveries. The land cost was obtained from the real state homepages and was based on the average selling price of the warehouses in each municipality. Guerin et al. (2021) also considered GDP, ISS, land cost, and total fleet for the São Paulo Metropolitan Region analysis.

Table 1 - Variables selected by the correlation analysis and respective source

\begin{tabular}{lll}
\hline Variables & & Source \\
\hline Phenomenon analysed & Warehouses & Santos (2015) \\
\hline & Population & IBGE (2020) \\
& Density Population & IBGE (2020) \\
& Employment Rate & IBGE (2020) \\
Socioeconomic variables & GDP per capita & IBGE (2020) \\
& Service fee percentage (ISSQN) & Municipalities homepage \\
& Companies & IBGE (2020) \\
& Shops & Open street maps \\
& Land cost & Real State Homepage \\
\hline \multirow{2}{*}{ Fleet variables } & Total Fleet & IBGE (2020) \\
& Truck fleet & IBGE (2020) \\
& Motorcycle fleet & IBGE (2020) \\
\hline
\end{tabular}

Some variables (e.g., population and density population; motorcycle fleet and total fleet; truck fleet and total fleet) are correlated. However, the inclusion of these variables represents some individual characteristics of the municipalities. Also, we used two similar data (companies and shops) from the different databases (IBGE and Open Street Maps) to evaluate the influence of the retail consumer market. Shops are directly variables related to the consumer market. However, it is impossible to confirm if all shops are included in this file since a collaborative database provides it. In another way, companies include all active businesses registered in a public database. The comparison of these variables could be helpful for future studies. Other variables could be included as infrastructure density, public transportation availability. We did not consider these variables due to the unavailability of data. 
The spatial correlation was measured by the Local Moran Index and Bivariate Moran Index. In addition, results were presented using the Local Indicator of Spatial Association. These spatial methods are detailed hereinafter.

\subsection{Local Moran Index}

We used the local Moran Index to identify local spatial correlation from variables considered in the analysis. Local Moran's Index (I) is an inferential spatial statistic used to calculate local spatial autocorrelation. The Moran I is measured by Equation 1 (Grekousis, 2020).

$$
I_{i}=\frac{x_{i}-\bar{X}}{m_{2}} \sum_{j} w_{i j}\left(x_{j}-\bar{X}\right)
$$

where: $\quad N \quad$ is the total number of observations (spatial object)

$x_{i} \quad$ is the attribute value of feature $\mathrm{i}$

$x_{j} \quad$ is the attribute value of feature $\mathrm{j}$

$\bar{X} \quad$ is the mean attribute

$w_{i j} \quad$ is the spatial weight feature $\mathrm{i}$ and $\mathrm{j}$

$m_{2} \quad$ is a constant for all areas. It is a consistent but not unbiased estimate of the variance.

$m_{2} \quad$ is defined by Equation 2.

$$
m_{2}=\frac{\sum_{j}\left(x_{j}-\bar{X}\right)^{2}}{n}
$$

As the local Moran Index is a local statistic, it is a multi-valued statistic. Each local value measures the relationship being examined in the vicinity of the studied region. The local Index also emphasises the differences and similarities to identify clusters and outliers (Fotheringham et al., 2002).

\subsection{Bivariate Moran's I}

We measured the Bivariate Moran Index to identify the warehouse and spatial lag variables' spatial correlation cluster. The Bivariate Moran Index measures the degree to which one variable is correlated with a different variable's spatial lag (average value at a nearby location) (Anselin, 2020). This Index is often used to assess how the linear association of two distinct variables varies in space and to trace spatiotemporal correlation (Grekousis, 2020). The Bivariate Moran's I is measured by Equation 3 (Anselin, 2020).

where $\quad w_{i j} \quad$ is the spatial weights matrix

$$
I_{i}^{B}=c x_{i} \sum_{j} w_{i j} y_{j}
$$

$$
\begin{array}{ll}
X_{i} & \text { is the variable at a location } \\
\sum_{j} w_{i j} y_{j} & \text { is the spatial lag of the other variable } \\
c & \text { is a constant estimate of the variance. }
\end{array}
$$

We calculated the opposite spatial correlation cluster considering the lagged warehouse to identify the spatial correlation and stability of the data to confirm the spatial correlation.

\subsection{Local Indicator of Spatial Association}

The Local Indicator of Spatial Association (LISA) is defined as a local statistic that satisfies the two requirements (Anselin,1995):

i. The LISA for each region indicates the extent of significant spatial clustering of similar values around that region, 
ii. The sum of the local LISAs is proportional to a global indicator of spatial association.

LISA is based on Moran I (local or bivariate). The local clusters are identified as contiguous locations where the LISA is significant (Anselin, 1995). In other words, LISA is a diagnosis of local instability, identifying patterns in the study area. There are four types of clusters: HighHigh, High-Low, Low-High, and Low-Low. A High-High cluster has a high Moran I value in its region, and the neighbouring region also has high Moran I values. The other cluster types have the same interpretation and are summarised in Table 2. High-low and low-high cluster types are considered outliers in the analysis.

Table 2 - Interpretation of cluster type in LISA

\begin{tabular}{lll}
\hline Cluster type & Region characteristic & Nearby region characteristic \\
\hline High-High $(\mathrm{H}-\mathrm{H})$ & High value & High value \\
High-Low $(\mathrm{H}-\mathrm{L})$ & High value & Low value \\
Low-High $(\mathrm{L}-\mathrm{H})$ & Low value & High value \\
Low-Low $(\mathrm{L}-\mathrm{L})$ & Low value & Low value \\
\hline
\end{tabular}

A significance confidence interval is established to evaluate the statistical significance. Clusters outside the significance confidence interval established are called not significant clusters. We considered a significance level of $95 \%$ and a p-value lower than 0.05 . The analyses were performed using the spdep package (Bivand, 2021) in the R environment.

\section{DESCRIPTION OF STUDY AREA}

The Belo Horizonte Metropolitan Region (BHMR) comprises 34 municipalities with 5.35 million inhabitants 2.03 million formal jobs in 158,595 companies (IBGE, 2020). Figure 1 shows the spatial pattern of variables. The warehouses are concentrated in few municipalities (Figure 1a). The temporal analysis (1995-2015) provided by Oliveira et al. (2018) showed the low logistics sprawl (1.2 km in the northwest direction). In this way, we can hypothesise that the characteristics of the cities of BHMR influenced the location of the warehouses. Most of the population (Figure 1b), companies (Figure 1g), shops (Figure 1h), and fleet (Figure 1j, 1k and 11) are concentrated in the core of the metropolitan area, mainly closer to Belo Horizonte. On the other hand, the employment rate (Figure 1d) and GDP per capita (Figure 1e) present a similar pattern. The average GDP per capita is $\mathrm{R} \$ 27.623,42$, showing a disparity in municipalities with a predominance of the service sector (low GDP per capita; e.g., Belo Horizonte) compared to the industry sector (high GDP per capita; e.g., Betim). The ISSQN (Figure 1f) and land cost (Figure 1i) did not present a similar pattern with other variables considered in the analysis. We observed an extensive range from land use data: $\mathrm{R} \$ 337.82$ (minimum), $\mathrm{R} \$ 3,118.50$ (average), and $\mathrm{R} \$ 13,703.30$ (maximum) are the sale price per square meter.

We highlighted some comparative variables: population and population density, companies and shops, the total fleet, motorcycle fleet and truck fleet. Population and population density have a similar pattern because the more populated municipalities coincide with those with lower rural area ratios and more job opportunities. The companies and shops similar pattern indicated a positive use of non-official sources when public data is not available. However, we suggest using these data only in planning steps while a research analysis is carried out. Finally, the fleet data presents a similar pattern showing the importance of choosing a variable representing the UFT phenomenon. 


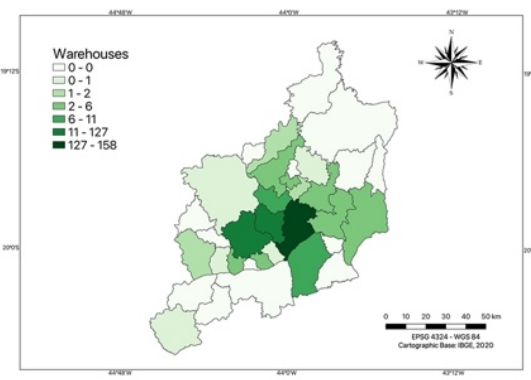

(a) Warehouse

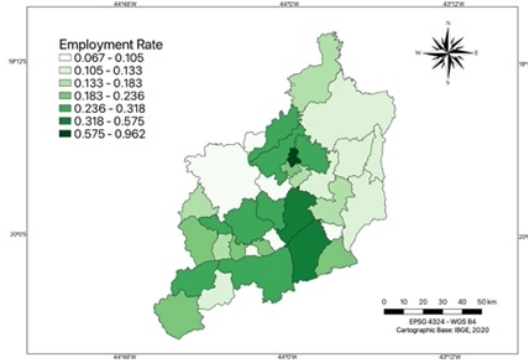

(d) Employment Rate

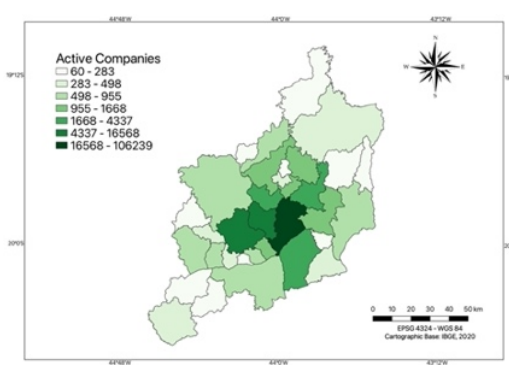

(g) Companies

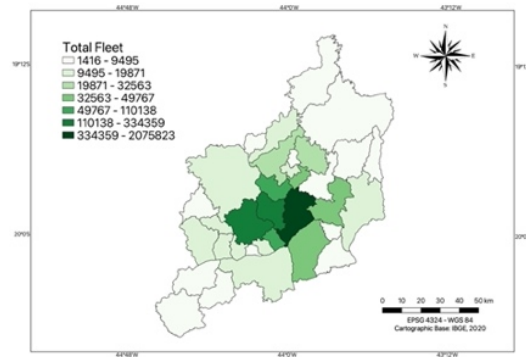

(j) Total Fleet

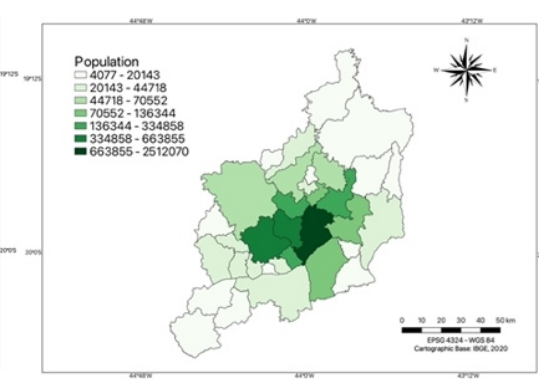

(b) Population

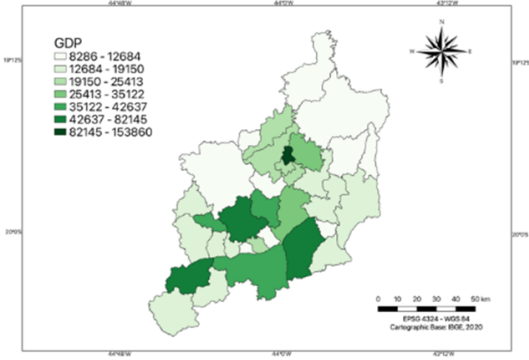

(e) GDP per capita

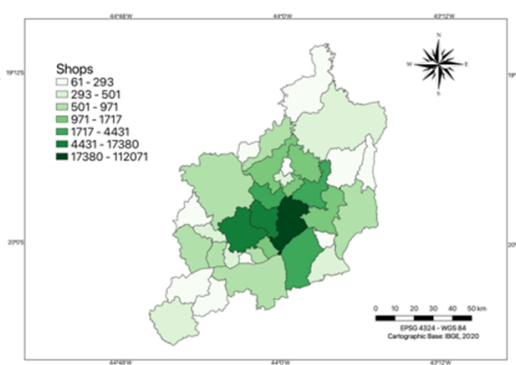

(h) Shops

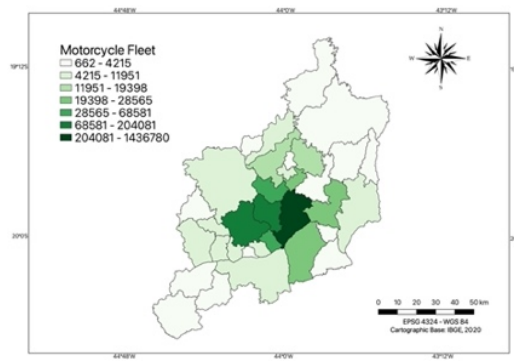

(k) Motorcycle Fleet

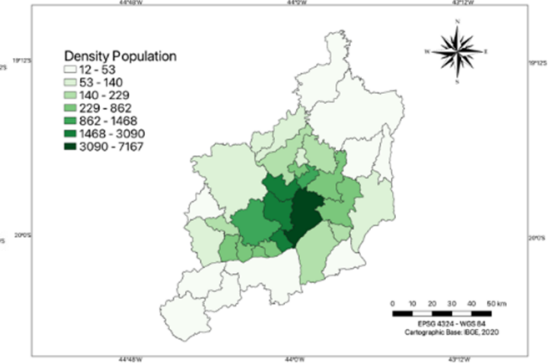

(c) Density Population

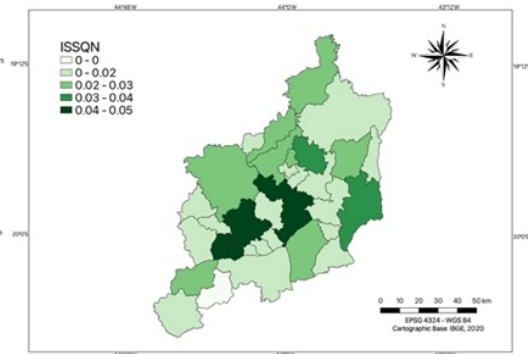

(f) ISSQN

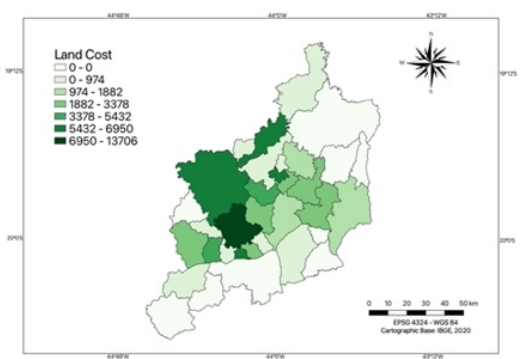

(i) Land Cost

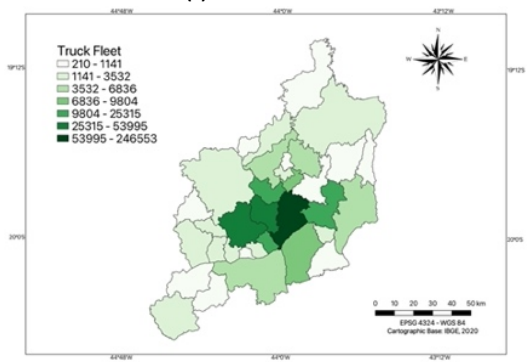

(I) Truck Fleet

Figure 1. Descriptive spatial variables

\section{RESULTS AND DISCUSSIONS}

\subsection{Spatial local autocorrelation}

Figure 1 presents the spatial autocorrelation of variables. Warehouses and truck fleet present the same H-H cluster (Belo Horizonte and Contagem). The density population presents a wide $\mathrm{H}-\mathrm{H}$ cluster than the population, indicating a stability pattern. GPD and employment rate did not present clusters (all are non-significant) due to the diversity pattern of these data in BHMR. Companies and shops also present the same $\mathrm{H}-\mathrm{H}$ cluster (Contagem). ISSQN also present a $\mathrm{H}-\mathrm{H}$ cluster in Contagem. The land cost has the biggest H-H cluster composed of Mario Campos, Betim, and Esmeraldas. From these municipalities, Betim concentrates more warehouses. 


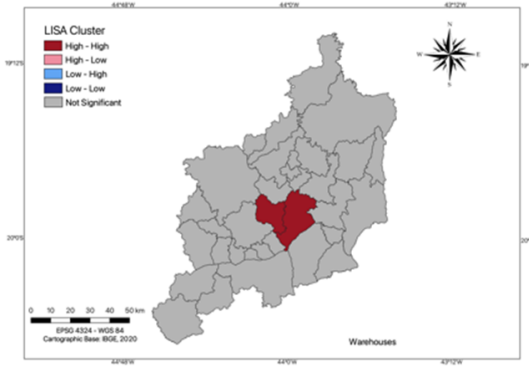

(a) Warehouse

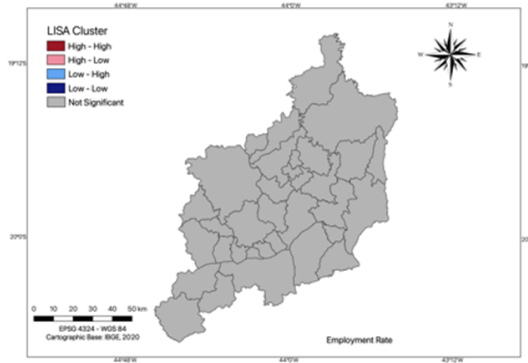

(d) Employment Rate

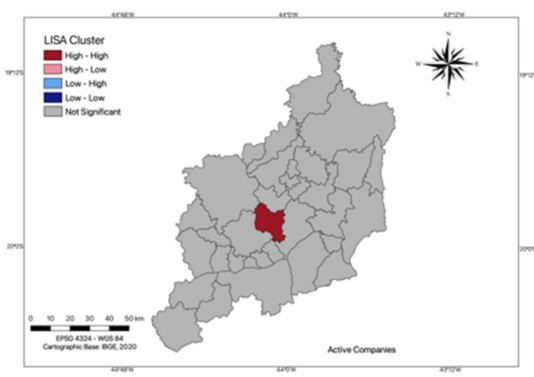

(g) Companies

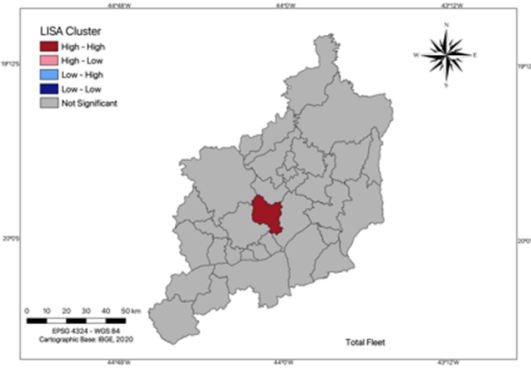

(j) Total Fleet

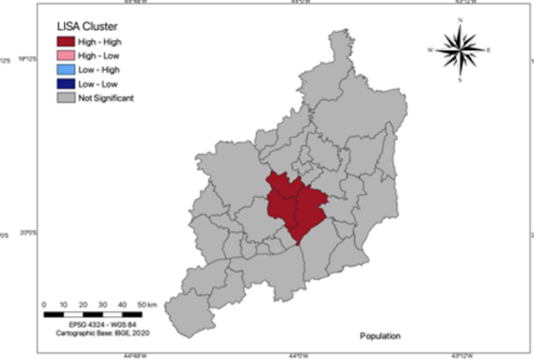

(b) Population

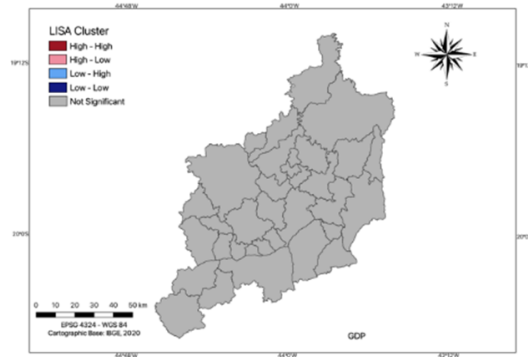

(e) GDP per capita

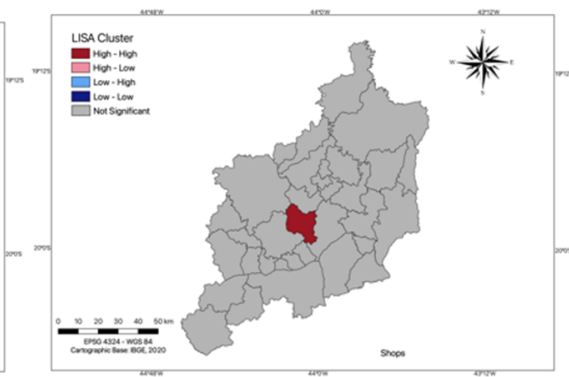

(h) Shops

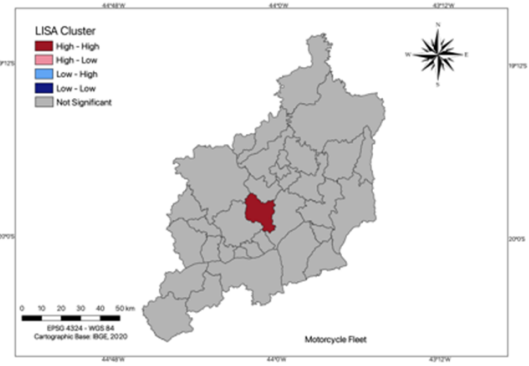

(k) Motorcycle Fleet

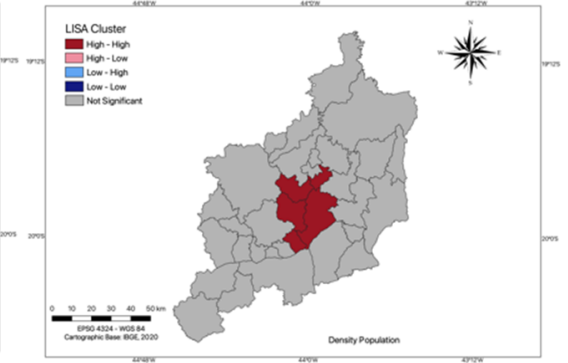

(c) Density Population

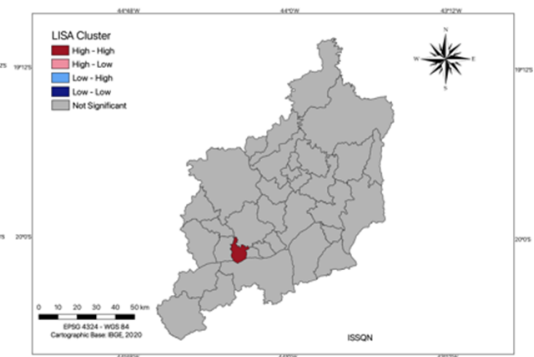

(f) ISSQN

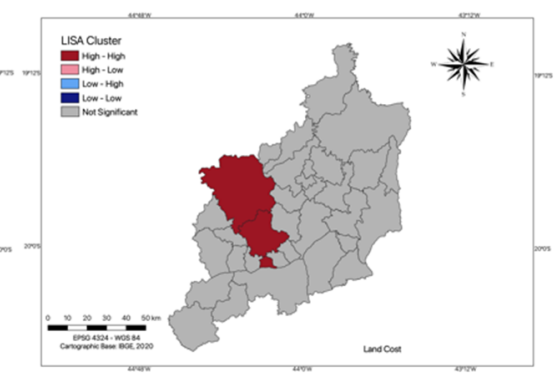

(i) Land Cost

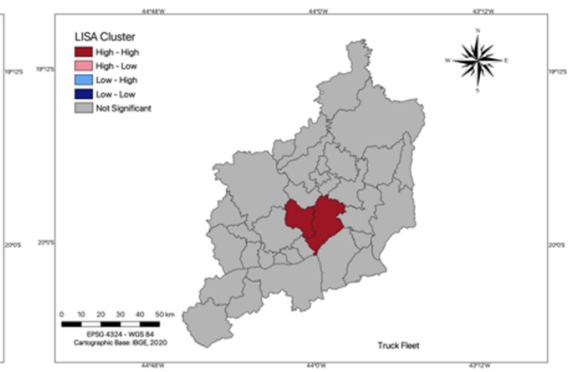

(I) Truck Fleet

Figure 2. Local spatial autocorrelation

The total fleet and motorcycle fleet have the same pattern: an H-H cluster in Contagem. On the other hand, the truck fleet has a wider cluster, including Belo Horizonte, indicating that the truck fleet has a more spatial correlation among the variables of the fleet group. Also, more municipalities included in the same cluster indicate a stability pattern of the variable. However, we highlight the importance of analysing the fleet composition of the metropolitan area to choose the appropriate fleet variable.

The majority of local correlation clusters included Contagem, which indicates this municipality as one of the most important in BHMR. Contagem is conurbation with Belo Horizonte, where $99 \%$ of the population living in the urban area. Its economy is based on trade and industry. BR381 (main roadway from São Paulo) and BR040 (main roadway from Rio de Janeiro and Brasília), providing a strategic location for new warehouses. Considering the 
strategic location of Contagem, is the spatial autocorrelation also observed with warehouse data? These results are presented hereafter.

\subsection{Spatial bivariate autocorrelation}

Figure 3 presents the bivariate spatial correlation between the warehouse, population, and density population. Again, we observe the same $\mathrm{H}-\mathrm{H}$ cluster considering population versus lagged warehouses, warehouses and lagged density population, and density population and lagged warehouses in Ribeirão das Neves and Ibirité, respectively.

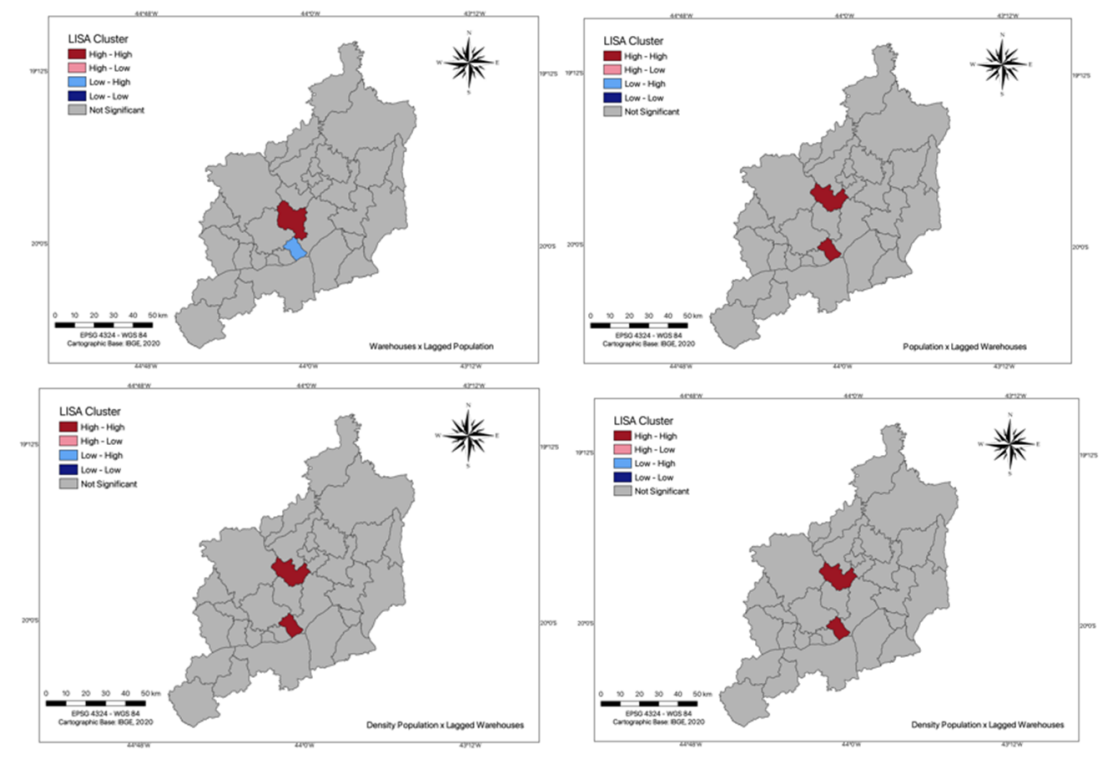

Figure 3. Bivariate spatial autocorrelation: population and density population

An H-H (Contagem) and an L-H cluster (Ibirité) is observed considering warehouses and lagged population, indicating the relation warehouses. The average population is low in Ibirité while high in the surroundings (an outlier results). The majority of Ribeirão das Neves and Ibirité residents live in urban areas (99\% and 98\%, respectively). Also, a conurbation is observed in Ibirité, Belo Horizonte, Contagem, and Ribeirão das Neves. Most of its residents' work and do their shopping in neighbouring cities. Therefore, results indicate spatial autocorrelation between warehouses and, mainly, population density.

Results presented in Figure 4 indicated lagged employment rate and lagged GDP does not have a cluster, showing non-influence of these variables on warehouse location. In contrast, an $\mathrm{L}-\mathrm{H}$ cluster is observed employment rate and GDP with the lagged warehouse. These outlier results indicate the employment rate and GDP are low in Ribeirão das Neves and Ibirité while the lagged warehouse is high in the surroundings. Additionally, lagged ISSQN has an $\mathrm{H}-\mathrm{H}$ cluster in Contagem. In contrast, lagged warehouse has an H-H cluster (Ribeirão das Neves), L-L cluster (Itaguara), and an L-H cluster (Ibirité). Itaguara has a larger rural area, local commercial activity, and low transportation movements with other cities in BHMR. Therefore, despite the importance of employment rate, GDP, and ISSQN (service fee percentage) for economic development, these spatial variables did not correlate to the warehouses in BHMR. A diverse spatial autocorrelation pattern was also identified by Guerin et al. (2021) for São Paulo Metropolitan Region. 


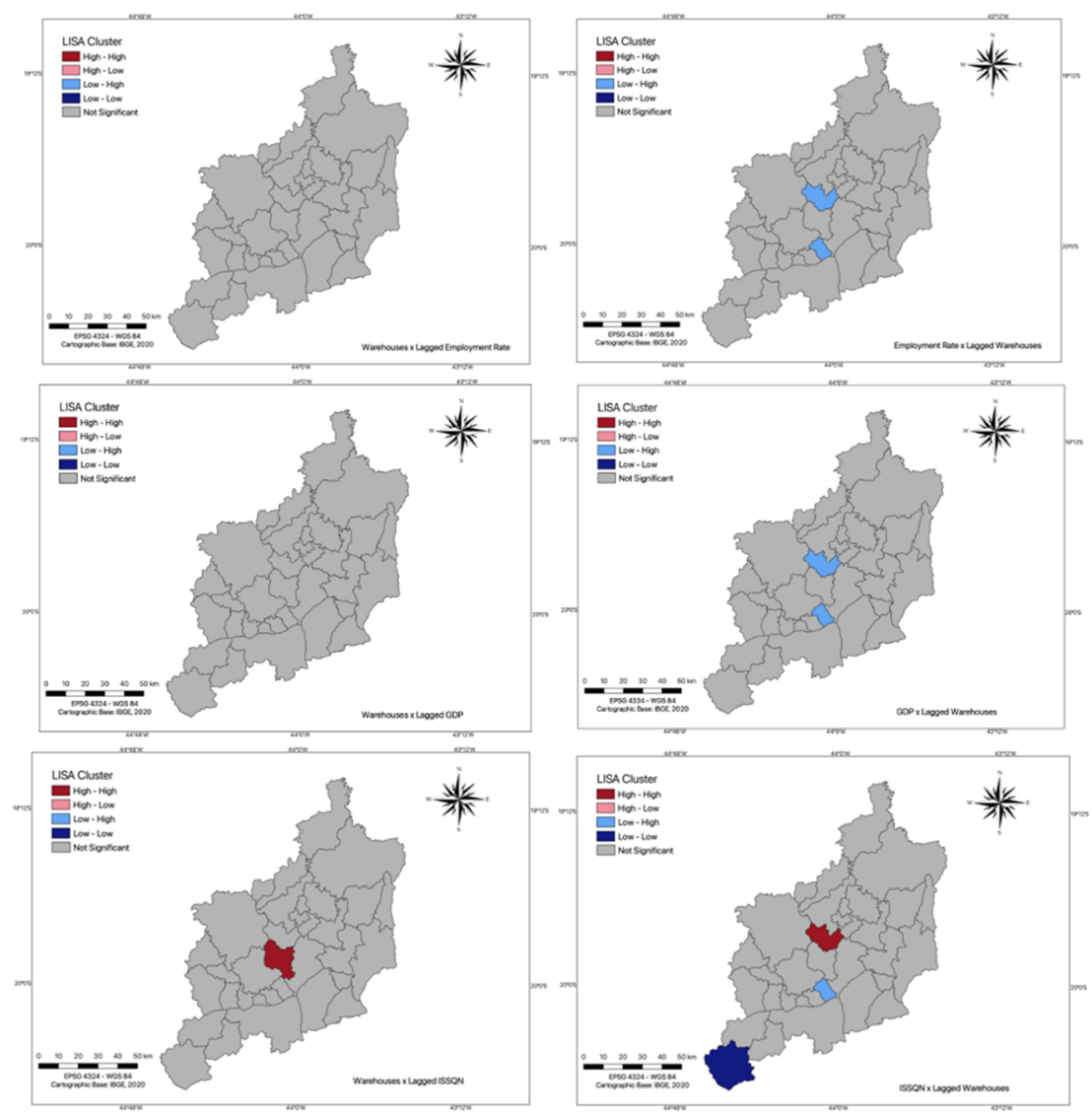

Figure 4. Bivariate spatial autocorrelation: employment rate, GDP per capita, and ISSQN

Also, outliers result with L-H clusters were identified considering companies and shops in Ibirité and Ribeirão das Neves (Figure 5). Additionally, a low-low (L-L) cluster was identified in Itaguara for lagged shops. Therefore, warehouses have no spatial correlation with companies and shops in BHMR. This surprising result shows that the warehouse is spatially correlated to residents (representing the e-consumers) than retail (represented by companies and shops).

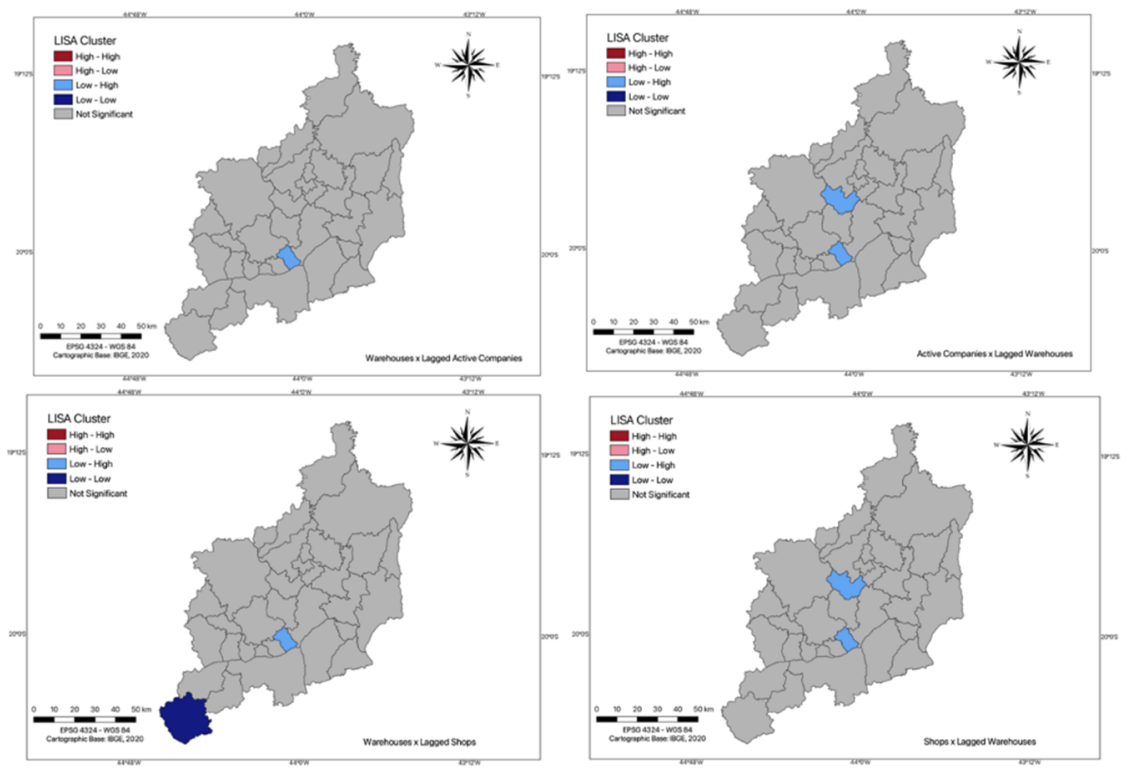

Figure 5. Bivariate spatial autocorrelation: companies and shops 
Figure 6 shows $\mathrm{H}-\mathrm{H}$ clusters between the warehouses and land cost in Contagem (considering warehouses and lagged land cost), Ribeirão das Neves and Ibirité (considering land cost and lagged warehouses). Also, an L-L cluster is identified in Itaguara, showing the low influence of municipalities far from the core of the metropolitan region in the warehouse location. In contrast, Contagem, Ribeirão das Neves, and Ibirité have importance in warehouse location. Since Belo Horizonte is the most populous BHRM city, we presume Belo Horizonte is the primary consumer market. However, due to the high population density, the land for a new warehouse is scarce and has a high cost. The closer and most connected cities are Contagem, Ribeirão das Neves and Ibirité, which presents medium land costs (see Figure 1i). The population density is not so high (see Figure 1b).

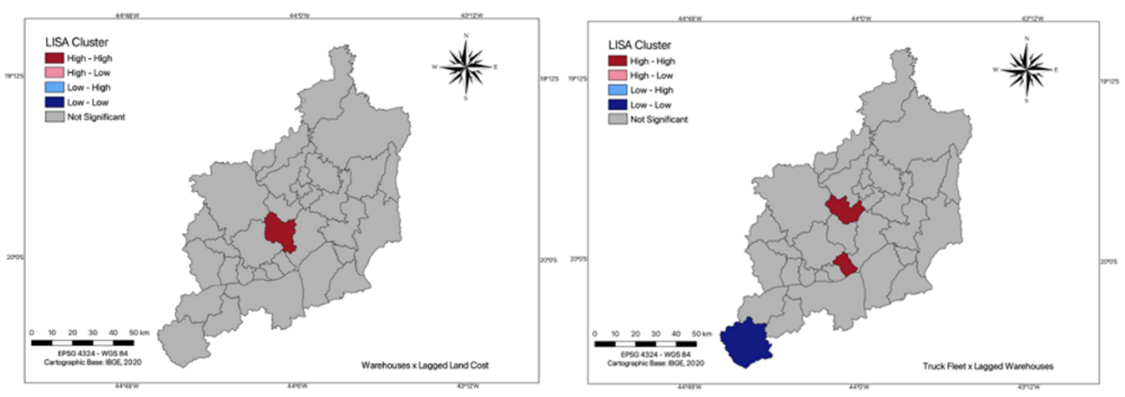

Figure 6. Bivariate spatial autocorrelation: land cost

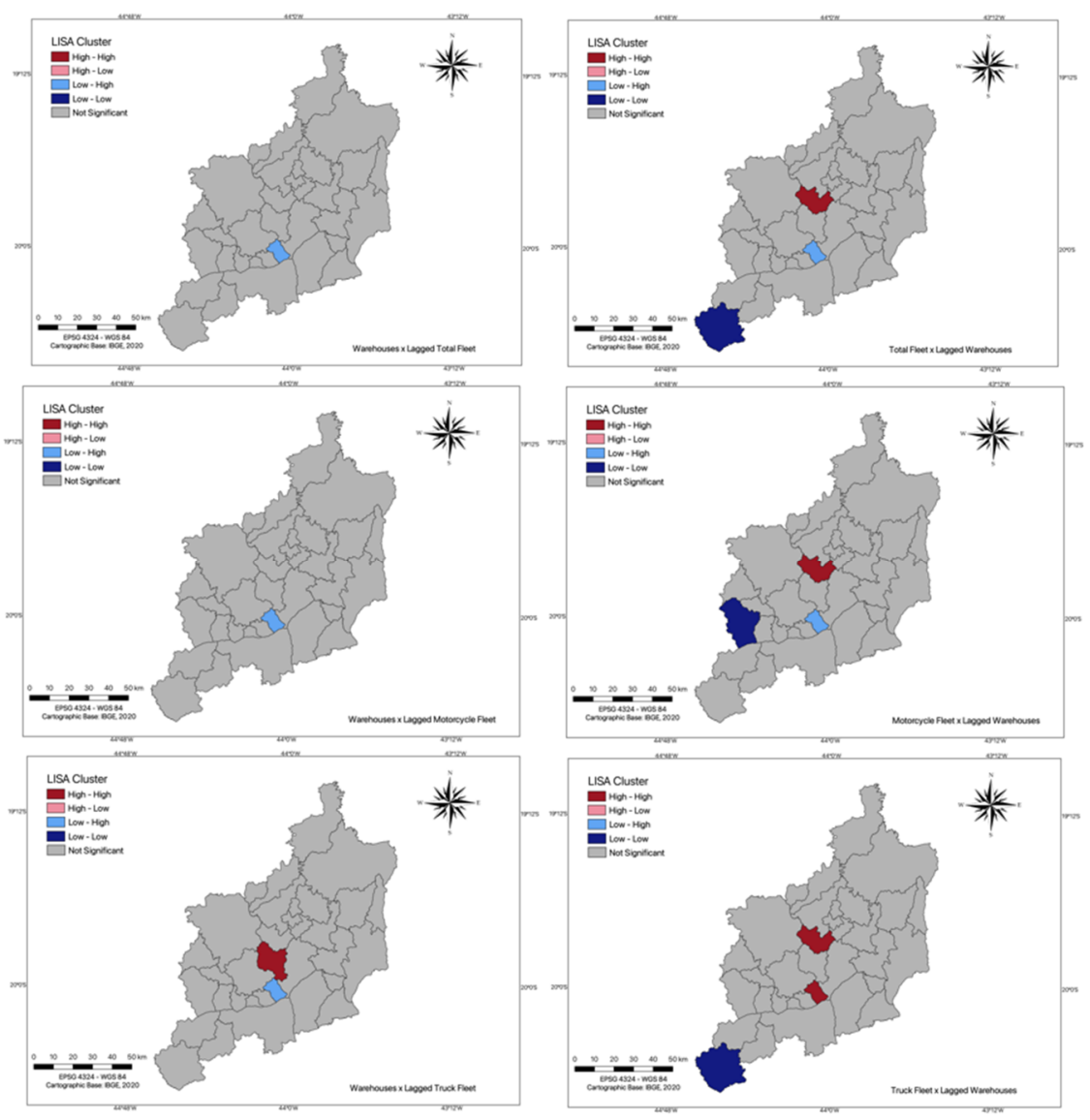

Figure 7. Bivariate spatial autocorrelation: fleet 
Finally, Figure 7 presents bivariate spatial autocorrelation considering fleet data. An $\mathrm{H}-\mathrm{H}$ cluster is observed in Ribeirão das Neves for all data fleet, considering lagged warehouse, while outliers are observed in Ibirité, except by truck fleet and lagged warehouse. Additionally, there are outliers: an H-H cluster in Contagem (warehouses and lagged total fleet) and Ibirité (truck fleet and lagged warehouses). The variation of the results shows a spatial correlation between the variables and lagged warehouses, but that there is spatial instability, mainly for the motorcycle fleet and total fleet. Therefore, fleet and warehouse are spatial autocorrelated variables converging to the Guerin et al. (2021) results.

\subsection{Discussion}

Results showed the influence of the characteristics of the cities on the warehouse location. Therefore, BHMR is the consequence of the political decision instead of the cities' characteristics and the conurbation. Thus, the spatial correlation of the characteristics of the city demonstrates the lack of similarity between them.

Guerin et al. (2021) found the cargo theft, GDP, road extension, and land cost are contributing factors in São Paulo Metropolitan Area (SPMA). These variables present an L-L cluster in the core of SPMA, including the metropolis São Paulo and an H-H cluster was identified in the surrounding municipalities. On the other hand, our results showed the population, ISSQN, land cost, and truck fleet contributing to the warehouses' location, with an L-L cluster not including the metropolis Belo Horizonte. Also, the data did not point to an $\mathrm{H}-\mathrm{H}$ cluster for Belo Horizonte metropolitan region. Thus, results show the heterogeneity of the characteristics of the metropolitan areas changes the contributing factors to the warehouses' location.

The warehouses are an essential logistical infrastructure to UFT. The strategic location of warehouses could reduce transportation costs and externalities (e.g., congestion and emission). The proximity of transportation infrastructure and to the consumer market contributes to the strategical location of warehouses, as found by Oliveira et al. (2018). However, our findings indicated the e-commerce market (represented by population) has a spatial autocorrelation to warehouses. On the other hand, companies and shops (a retail market proxy) have no spatial autocorrelation. Probably, the dynamism and complexity of e-commerce distribution are a factor to be included in further analyses. However, density areas are more spatial autocorrelated to the warehouses, indicating the dense metropolitan areas can attract new warehouses.

The ISSQN is a service tax that the municipalities could use to attract more companies and trade transactions. However, the percentage used by BHMR municipalities is not an attractive factor for warehouses since the warehouses did not generate commercial transactions. Guerin et al. (2021) also considered the ISSQN and found outliers clusters (H-L and L-H). Other taxrelated land use (as Property and Urban Territorial Tax, IPTU) or fleet (Motor Vehicle Property Tax, IPVA) could have more spatial correlation and be considered in further analysis. However, since a diverse pattern was observed comparing our results with Guerin et al. (2021), we suggest considering the local characteristics and dynamism of metropolitan regions to include service tax in the further analysis.

Land cost is a crucial variable for warehouses location. As reported in the literature, our findings reinforce the importance of logistics zoning associated with land use and real estate policies. The warehouses are located in BHMR municipalities with a medium land cost. Contagem, Ribeirão das Neves, and Ibirité. Brazil does not have experience with the logistics real estate sector aligned to land use policies for logistics and economic development. 
For example, Germany has an annual report about its logistics and real estate sector (see more information in https://logistik-und-immobilien.de). France also has private (Afilog) and academic initiatives (Logistics City Chair, a partnership between University Gustave Eiffel, Sogaris, and Poste-Immo) to develop the sector of the logistics and real estate initiatives. The development of similar initiatives could provide knowledge and methodological tools for the UFT' stakeholders.

Finally, despite the importance of motorcycles for UFT, only the truck fleet is spatially correlated with warehouses. Traditionally, freight vehicles are the most used for urban delivery. However, we observed a renewed fleet with smaller freight vehicle capacity such as Fiorino or vans.

\section{CONCLUSION}

This paper analysed the spatial correlation of characteristics of cities in a metropolitan region and the warehouses' location. We performed a case study in the Belo Horizonte metropolitan region. The municipalities' socioeconomic and fleet data were analysed using the Local Moran Index and Bivariate Moran Index statistics.

Results indicated the warehouses are spatially correlated with the density population, land cost, and freight vehicles fleet. The difference between the results from Guerin et al. (2021) and those found in this paper highlighted the importance of not generalising them due to the influence of the local characteristics on warehouse location. Each metropolitan context is unique, and the heterogeneous characteristics could not provide a spatial pattern. Also, our findings encourage the re-thinking of the urban planning process, including the logistics and real estate sector in the planning decisions. Integrated urban planning could promote synergies between the sectors contributing to economic development.

For future research, we suggest elaborating an UFT open database to reduce the limitations related to UFT-data. Also, we suggest including other variables as the transportation network, the public transportation network, and job opportunities in future works, as considered by Jaller et al. (2017) and Guerin et al. (2021). Also, we suggest the use of a density population instead of a population in the analysis. We observed the density population represents better this characterises of the cities. Finally, since our results did not fully converge to Guerin et al. (2021), we suggest investigating the pattern of warehouse location in other metropolitan regions.

\section{ACKNOWLEDGEMENTS}

We thank you for CNPq, CAPES and FAPEMIG to support this research.

\section{REFERENCES}

Aljohani, K. and R.G. Thompson (2016) Impacts of logistics sprawl on the urban environment and logistics: Taxonomy and review of literature. Journal of Transport Geography, 57, 255-263. DOI: 10.1016/j.jtrangeo.2016.08.009

Allen, J.; M. Browne; and T. Cherrett (2012) Investigating relationships between road freight transport, facility location, logistics management and urban form. Journal of Transport Geography, 24, 45-57. DOI: 10.1016/j.jtrangeo.2012.06.010

Anselin, L. (1988) Spatial Econometrics: Methods and Models. Studies in Operational Regional Science. Springer Science: Dordrecht.

Anselin, L. (1995) Local Indicator of Spatial Association - LISA. Geographical Analysis, 72(2), 93-115. D0I: 10.1111/j.15384632.1995.tb00338.x

Anselin, L. (2020) Local Spatial Autocorrelation: Multivariate Local Spatial Autocorrelation. Available at: https://geodacenter.github.io/workbook/6c_local_multi/lab6c.html (Accessed: 05 April 2021)

Bivand, R. (2021). Spatial Dependence: Weighting Schemes, Statistics [R package spdep version 1.1-7]. [online] Cran. r-project.org. https://cran.r-project.org/web/packages/spdep/index.html (Accessed: 05 April 2021) 
Bracarense, L.S.F.P., T.A. Assis, L. K. Oliveira, and R.L.M. Oliveira (2018). Logistics sprawl assessment applied to locational planning: a case study in Palmas (Brazil). In: Taniguchi, E., Thompson, R.G. (Eds.), City Logistics 2: Modeling and Planning Initiatives, 20. ISTE Ltd, John Wiley \& Sons, Inc, London, Hoboken, pp. 333-349. DOI: 10.1002/9781119425526.ch20

Dablanc, L. and D. Rakotonarivo, D. (2010) The impacts of logistics sprawl: how does the location of parcel transport terminals affect the energy efficiency of goods' movements in Paris and what can we do about it? Procedia -Social and Behavioral Science, 2, 6087-6096. DOI: 10.1016/j.sbspro.2010.04.021

Dablanc, L.; G. Giuliano; K. Holliday; and T. O’Brien (2013) Best Practices in Urban Freight Management Lessons from an International Survey. Transportation Research Record: Journal of the Transportation Research Board, 2379, 29-38. DOI: 10.3141/2379-04

Dablanc, L.; S. Ogilvie; and A. Goodchild (2014) Logistics sprawl: differential warehousing development patterns in Los Angeles, California, and Seattle, Washington. Transportation Research Record, 2410(1), 105-112. D0I: 10.3141/2410-12

Demirel, T.; N.Ç. Demirel; and C. Kahraman, C. (2010) Multi-criteria warehouse location selection using Choquet integral. Expert Systems with Applications, 3, 3943-3952. DOI: 10.1016/j.eswa.2009.11.022

Dubie, M.; K.C. Kuo; G. Giron-Valderrama; and A. Goodchild (2020). An evaluation of logistics sprawl in Chicago and Phoenix. Journal of Transport Geography, 88, 10229. DOI: 10.1016/j.jtrangeo.2018.08.008

Fortheringham, A.S.; C. Brunsdon; and M. Chasrlton (2002) Geographically Weighted Regression: The analysis of spatially varying relationships. West Sussex, England: John Wiley and Sons, LTD.

Giuliano, G. and S. Kang (2018) Spatial dynamics of the logistics industry: evidence from California. Journal of Transport Geography, 66, 248-258. DOI: 10.1016/j.jtrangeo.2017.11.013

Giuliano, G.; S. Kang; and Q. Yuan (2018) Using proxies to describe the metropolitan freight landscape. Urban Studies, 55(6), 1346-1363. DOI: $10.1177 / 0042098017691438$

González-Feliu, J. (2018) Urban Logistics and Spatial Territorial Intelligence Indicators: State of The Art, Typology and Implications for Latin American Cities. INTERFASES, 11, 136-176. DOI: 10.26439/interfases2018.n011.2958

Grekousis, G. (2020). Spatial Analysis Methods and Practice: Describe - Explore - Explain through GIS. Cambridge: Cambridge University Press.

Guerin, L.; J.G.V Vieira; R.L.M. Oliveira; L.K. Oliveira; H.E.M. Vieira; and L. Dablanc, (2021). The geography of warehouses in the São Paulo Metropolitan Region and contributing factors to this spatial distribution. Journal of Transport Geography, 91, 102976. DOI: $10.1016 / j$.jtrangeo.2021.102976

Heitz, A.; L. Dablanc; and L.A. Tavasszy (2017). Logistics sprawl in monocentric and polycentric metropolitan areas: the cases of Paris, France, and the Randstad, the Netherlands. Region, 4, 93-107. DOI: 10.18335/region.v4i1.158

Heitz, A.; L. Dablanc; J. Olsson; I. Sanchez-Diaz; and J. Woxenius, J. (2020). Spatial patterns of logistics facilities in Gothenburg, Sweden. Journal of Transport Geography, 88, 102191. DOI: 10.1016/j.jtrangeo.2018.03.005

Heitz, A.; P. Launay; and A. Beziat (2019) Heterogeneity of logistics facilities: an issue for a better understanding and planning of the location of logistics facilities. European Transport Research Review, 11(5), 1-20. DOI: 10.1186/s12544-018-0341-5

IBGE (2020) IBGE Cidades. Available at: https://cidades.ibge.gov.br (Accessed: 29 April 2021)

Jakubicek, P. and C. Woudsma (2011) Proximity, land, labor and planning? Logistics industry perspectives on facility location. Transportation Letters, 2, 161-173. DOI: 10.3328/TL.2011.03.03.161-173

Jaller, M.; L. Pinedaand; D. Phong (2017). Spatial Analysis of Warehouses and Distribution Centers in Southern California. Transportation Research Record, 2610, 44-53. DOI: 10.3141/2610-06

Kang, S. (2020) Why do warehouses decentralize more in certain metropolitan areas? Journal of Transport Geography, 88, 102330. DOI: $10.1016 /$ j.jtrangeo.2018.10.005

Klauenberg, J., Elsner, E.-A. and Knischewski, C. (2020) Dynamics of the spatial distribution of hubs in groupage networks The case of Berlin. Journal of Transport Geography, 88, 102280. DOI: 10.1016/j.jtrangeo.2018.07.004

Leigh, N.G. and N.Z. Hoelzel (2012) Smart growth's blindside. Journal of the American Planning Association, 78(1), 87-103. DOI: $10.1080 / 01944363.2011 .645274$

Lindsey, C.; H.S. Mahmassani; M. Mullarkey; T. Nash; and S. Rothberg (2014) Industrial space demand and freight transportation activity: exploring the connection. Journal of Transport Geography, 37, 93-101. DOI: 10.1016/j.jtrangeo.2014.04.009

Oliveira, L.K.; G.G.F. Araújo; and I.K. Oliveira (2019) How to explain the location of logistics warehouses from the urban quality-of-life index and the local supply index? WSB Journal of Business and Finance, 53(2), 15-21. D0I: 10.2478/wsbjbf2019-0018

Oliveira, L.K.; O.R. Santos; R.A.A. Nóbrega; R.L.M. Oliveira; and L. Dablanc (2017) Análise do espraiamento logístico: Um estudo para a região metropolitana de Belo Horizonte. Transportes, 25(4), 42-56. DOI: 10.14295/transportes.v25i4.1214

Oliveira, L.K.; O.R. Santos; R.L.M. Oliveira; and R.A.A. Nóbrega (2018) Is the Location of Warehouses Changing in the Belo Horizonte Metropolitan Area (Brazil)? A Logistics Sprawl Analysis in a Latin American Context. Urban Science, $2(2), 43$. DOI: $10.3390 /$ urbansci2020043

Sakai, T.; K. Kawamura; and T. Hyodo (2016). Logistics facility distribution in Tokyo Metropolitan area: experiences and policy lessons. Transportation Research Procedia, 12, 263-277. DOI: 10.1016/j.trpro.2016.02.064

Santos, O.R. (2015) Influência da localização de instalações logísticas na região metropolitana de Belo Horizonte. Dissertação. Universidade Federal de Minas Gerais, Belo Horizonte.

Sousa, L.M., and L.K. Oliveira (2020). Influence of Characteristics of Metropolitan Areas on the Logistics Sprawl: A Case Study for Metropolitan Areas of the State of Paraná (Brazil). Sustainability 12(22), 9779. D0I: 10.3390/su12229779 
Verhetsel, A.; R. Kessels; P. Goos; T. Zijlstra; N. Blomme; and J. Cant (2015). Location of logistics companies: a stated preference study to disentangle the impact of accessibility. Journal of Transport Geography, 42, 110-121. DOI: 10.1016/j.jtrangeo.2014.12.002

Woudsma, C. and P. Jakubicek (2020) Logistics land-use patterns in metropolitan Canada. Journal of Transport Geography, 88, 102381. DOI: $10.1016 /$ j.jtrangeo.2019.01.001

Woudsma, C.; P. Jakubicekb; and L. Dablanc (2016). Logistics sprawl in North America: methodological issues and a case study in Toronto. Transportation Research Procedia, 12, 474-488. DOI: 10.1016/j.jtrangeo.2014.12.002

Yuan, Q. and Zhu, J. (2019) Logistics sprawl in Chinese metropolises: Evidence from Wuhan. Journal of Transport Geography, 74, 242-252. DOI: 10.1016/j.jtrangeo.2018.11.019 